\title{
Pulmonary Artery Agenesis: A Case Series
}

\author{
Meltem Ağca, Servet Bulum, Hakan Günen, Fatma Tokgöz, Tülay Yarkın, \\ Mine Demir
}

Süreyyapaşa Chest Diseases and Thoracic Surgery Training and Research Hospital, İstanbul

\begin{abstract}
Pulmonary artery agenesis is a rare congenital abnormality in which atresia was encountered in the short segment of the right or left pulmonary arteries. It can be isolated or associated with cardiac abnormalities such as tetralogy of Fallot, septal defects or pulmonary stenosis. The majority of cases are diagnosed in childhood whereas some cases yield no symptoms until adulthood. We evaluated retrospectively 5 pulmonary artery agenesis cases diagnosed in our clinics between 1998-2010 with respect to the literature.
\end{abstract}

Keywords: Angiography, echocardiography, pulmonary artery agenesis, vascular abnormalities

Received Date: 21.08 .2013 Accepted Date: 07.12.2013

Address for correspondence

Meltem Ağca, Süreyyapaşa Chest Diseases and Thoracic Surgery Training and Research Hospital, İstanbul, Turkey

E-mail: agcameltem@yahoo.com

This work is licensed under a Creative Commons Attribution-NonCommercia 4.0 International License.

DOI: 10.5152/ejp.2014.83436

-Available online at www.eurasianjpulmonol.com

\section{INTRODUCTION}

Isolated one-sided pulmonary artery agenesis is a rare congenital anomaly in the proximal short segment of the right or left pulmonary artery. Generally, the distal parts of the artery at the hilus are protected (1). It can occur with Fallot tetralogy, septal defects, or pulmonary stenosis as well as by itself. It can often be identified during childhood years, but it can hide symptoms until the late adult ages. When it presents, the symptoms are recurrent infections, hemoptysis, shortness of breath, restricted exercise, and chest pain are observed. The diagnosis is hard because of the lack of specific symptoms and rarity of the disease. It is important to diagnose this disease at early ages because it causes serious complications such as massive hemoptysis, pulmonary hypertension, respiratory failure, and bronchiectasis (2).

The mortality rate of this rare anomaly is high because of its complications. We retrospectively analyzed five cases of pulmonary artery agenesis at older ages in accordance with the literature knowledge.

\section{CASE PRESENTATIONS}

\section{Case1}

A 37-year-old male patient was admitted to our emergency department with complaints of fever, shortness of breath, yellow phlegm, and hemoptysis occurring occasionally. It was learned from his history that he had been treated for bronchiectasis. Because a left pulmonary artery shadow was not seen on posteroanterior (PA) chest X-ray (Figure 1a), echocardiography (ECO) was performed for vein malformation. A mild expansion in the right atrium and right ventricle and a systolic pulmonary artery pressure (PAPs) of $50 \mathrm{mmHg}$ were observed. Chest computerized tomography (CT) (Figure 1b) revealed varicose and cystic bronchiectasis in the left lung, nearly total volume loss, rising in the left diaphragm, and replacement toward the left in mediastinal structures. In the spirometric examination, mild restrictive and moderate obstructive [FVC: $3.29 \mathrm{~L}$ (72\% of expected), FEV 1 : $1.90 \mathrm{~L}$ (51\% of expected), $\mathrm{FEV}_{1}$ /FVC: $57.7 \%$ (not expected)] respiratory dysfunction was detected. In the bronchoscopic analysis of the patient, the mouth of the left upper lobe was found to be narrowed in the shape of a lip. The left lung was totally hypoplasic and hypoperfused on ventilation perfusion (V/Q) scintigraphy 

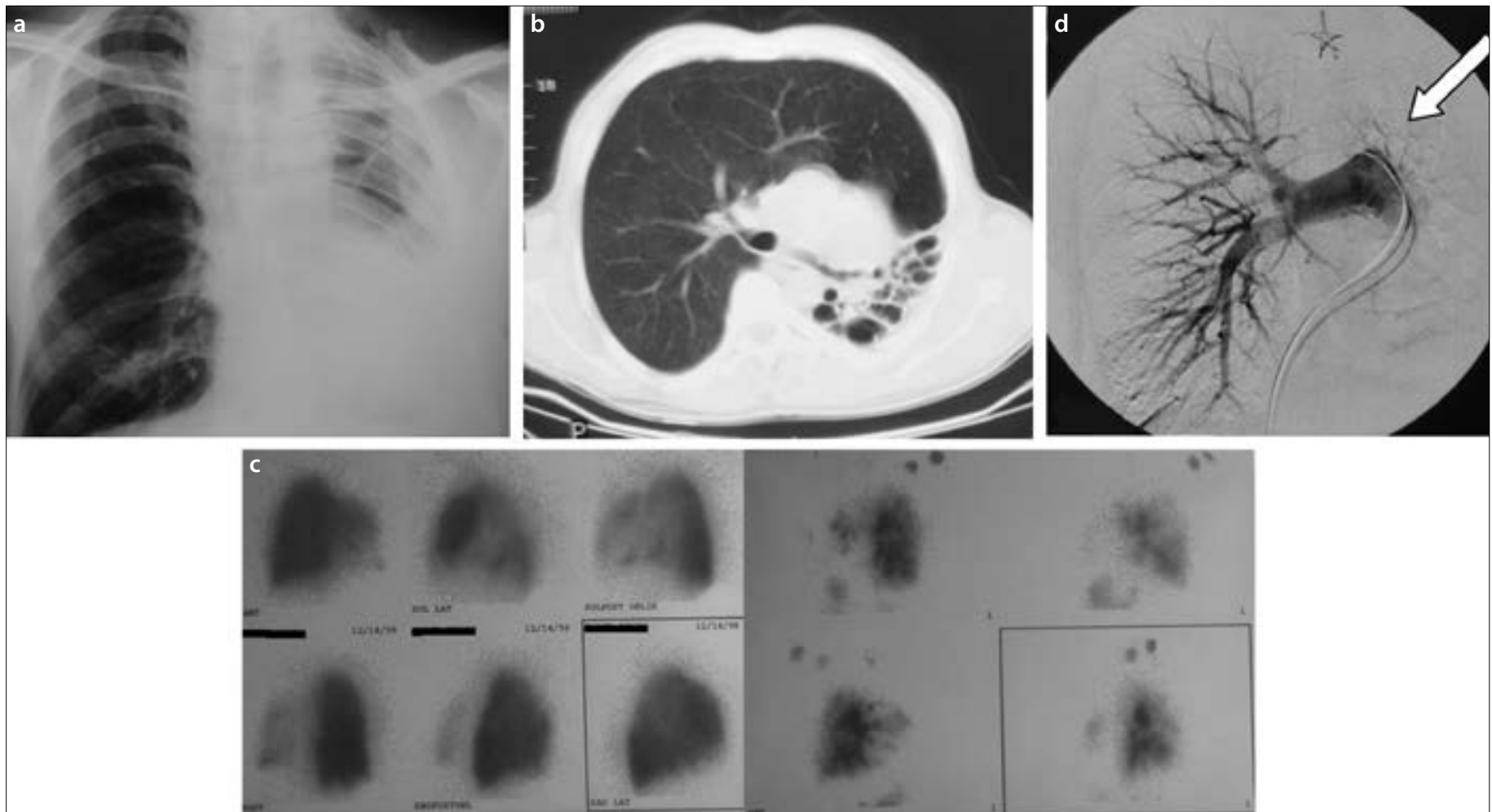

Figure 1.a-d. Case 1: Loss of volume in the left lung and replacement toward the left in mediastinal structure on PA chest X-ray (a); Chest $\mathrm{X}$-ray revealed loss of volume in the left lung and cystic bronchiectasis (b); V/Q scintigraphy revealed hypoplasic and hypoperfused left lung (c); Invasive pulmonary angiography revealed left main pulmonary artery agenesis (d)

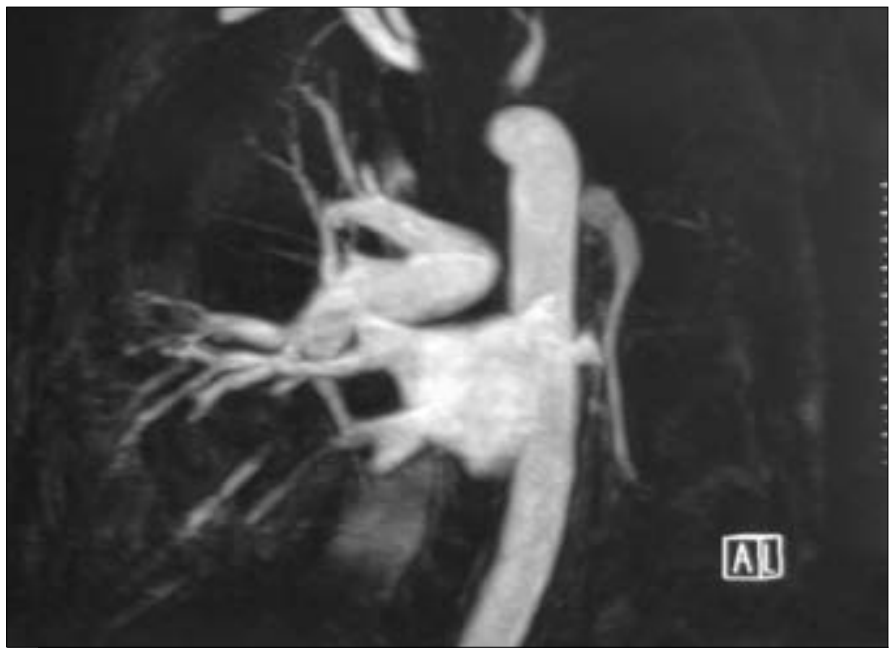

Figure 2. Case 2: Chest MR angiography revealed upper branch agenesis of left pulmonary artery

(Figure 1c). Invasive pulmonary angiography of the patient (Figure 1d) revealed that the left pulmonary artery was closed starting from the ostium level and the patient was diagnosed with left pulmonary artery agenesis. Left pneumonectomy was applied to the patient who experienced infection and hemoptysis seizures frequently.

\section{Case 2}

A 70-year-old male patient presented with complaints of shortness of breath, restricted exercise, and hemoptysis. From his history, it was learned that he had been experiencing recurrent infection seizures since his childhood and was hospitalized for treatment. A high level of restriction [FVC: $0.93 \mathrm{~L}$ (33\% of the expected), $\mathrm{FEV}_{1}: 0.82 \mathrm{~L}$ ( $31 \%$ of the expected), $\mathrm{FEV}_{1} / \mathrm{FVC:} 88 \%$ ] was detected in the spirometric analysis. Because the volume of the left lung was low on PA chest X-ray, bronchoscopic analysis was performed, and lingula on the left and deformation in the lower lobe bronchus were observed. Quantitative perfusion scintigraphy revealed that the left lung participated in the perfusion at the rate of $2 \%$ and the right lung participated at the rate of $98 \%$. Chest CT revealed a significant decrease in the volume of the left lung and air cysts on the left in the right lung and the mediastinum replaced toward left. Magnetic resonance (MR) angiographic analysis (Figure 2) revealed no vascular filling at the upper branch of the left pulmonary artery. Blood transfusion was performed for the patient who developed massive hemoptysis (hemoglobin $8.6 \mathrm{~g} / \mathrm{dL}$, hematocrit $28.5 \%$ ). The patient whose general condition improved was discharged.

\section{Case 3}

A 53-year-old female patient presented with complaints of shortness of breath and phlegm. In her history, there were hospital stays due to frequent respiratory tract infections. On her PA chest X-ray, it was monitored that the volume of the left lung was decreased, the left lung was more opaque than the right one, and the left pulmonary artery shadow was not seen. On her chest CT, mediastinal structures were replaced toward the left. There were air cysts on the affected side and cystic bronchiectasis in the upper lobes of the opposite lung. Pulmonary arterial pressure was within normal intervals on ECO and there was no sign of cardiac anomalies. Chest MR angiography was performed in the patient and agenesis was detected in the left main pulmonary artery. 


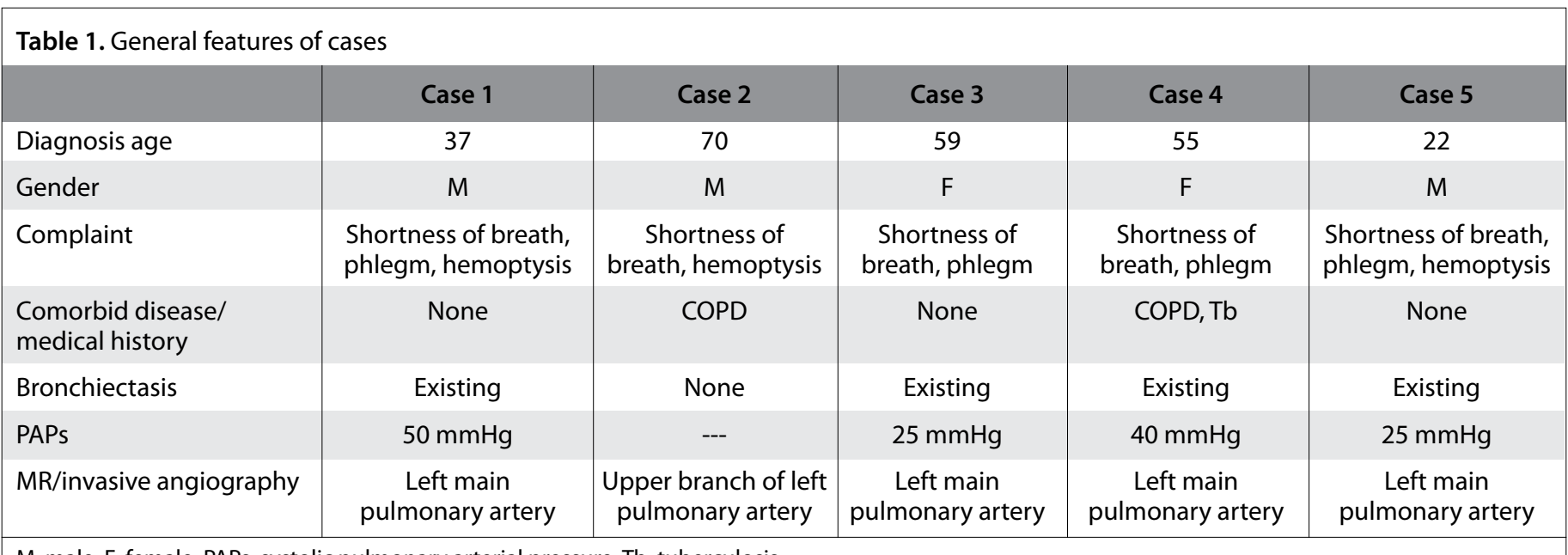

M: male; F: female; PAPs: systolic pulmonary arterial pressure; Tb: tuberculosis

\section{Case 4}

A 55-year-old female patient presented with complaints of high fever and purulent phlegm. It was learned from her history that she had undergone tuberculosis treatment 30 years previously and was hospitalized frequently because of bronchiectasis and respiratory failure. The patient who received bronchodilator and antihypertensive treatments did not have a history of smoking. On PA chest X-ray, volume loss in the left lung, replacement toward the left at the trachea, and heterogeneous infiltration in all zones on the right side were observed. Restriction was detected on spirometric assessment [FVC: $1.39 \mathrm{~L}$ ( $41 \%$ of expected), $\mathrm{FEV}_{1}: 1.18 \mathrm{~L}$ ( $40 \%$ of expected), $\mathrm{FEV}_{1} / \mathrm{FVC}$ : $84 \%$ ]. On the ECO, a PAPs of $40 \mathrm{mmHg}$, an ejection fraction (EF) of $55 \%$, moderate mitral insufficiency, minimal aortic insufficiency, and mild tricuspid insufficiency were detected. On the MR angiography, fillings of lobber and segmental arteries were remarkably decreased and thus, left main pulmonary artery agenesis was diagnosed. The patient who was given long term oxygen treatment according to the arterial blood gas results was discharged afterward.

\section{Case 5}

A 22-year-old male patient was admitted with complaints of shortness of breath, purulent phlegm, and hemoptysis. It was learned that the patient had been treated and followed up for bronchiectasis until he presented to our clinic. On PA chest X-ray, volume loss in the left lung, rising in the left hemidiaphragm, and replacement toward the left at the heart, mediastinum, and trachea were observed. On the chest $\mathrm{CT}$, diffuse varicosis and cystic bronchiectasis and a decrease in vascular structures were detected. No sign of pathologic findings was found on ECO. On the invasive pulmonary angiography that was performed for a better evaluation of the vascular structures, agenesis was detected in the left main pulmonary artery. The patient who had infection seizures occasionally is well, in general, and is under our care.

\section{DISCUSSION}

We presented the phenomena of left pulmonary artery agenesis detected in five patients aged between 22 and 70 years, with their clinical and radiological features.

One-sided pulmonary artery agenesis is the absence of proximal parts of the right or left pulmonary arteries and was first described by Frantzel during a necropsy in Germany in 1868 (3). Because pul- monary artery agenesis can remain asymptomatic for long years, it is difficult to identify the actual prevalence. The estimated prevalence is approximately $1 / 200,000$ (2).

Pulmonary arteries develop from the $6^{\text {th }}$ aortic arch at the $16^{\text {th }}$ week of normal embryological development. The proximal of the $6^{\text {th }}$ aortic arch constitutes the proximal part of the right and left pulmonary arteries. While on the right side, the connection of the distal part with the arch disappears and the left side continues by setting a connection with the ductus arteriosus. Pulmonary artery agenesis occurs because of the rotation in the connection of the affected part with the aortic arch and the malfunctions at the migration (4). Some authors use the term "proximal interruption of pulmonary artery" instead of "agenesis" for this abnormality. Despite the fact that the intraparanchymal distal part of the pulmonary artery is small, it is protected $(5,6)$.

It is difficult to establish the diagnosis of pulmonary artery agenesis at adult ages. The lack of specific symptoms, rarity, and benign clinical course make it harder to suspect this disease and thus, delay diagnosis. In a review of 108 cases, it was recognized that it took more than 30 years to diagnose patients (7). In this report, the features of the five cases that were diagnosed with pulmonary artery agenesis and were followed up between the years of 1998 and 2010 are presented in Table 1. At the time of diagnosis, the youngest patient was 22 years old and the oldest patient was 70 years old.

Right pulmonary artery agenesis is more common than left pulmonary artery agenesis, and it is generally seen as alone. Congenital cardiovascular abnormalities such as Fallot tetralogy, truncus arteriosus, septal defects, and patent ductus arteriosus may be present with left pulmonary arterial agenesis (5). In all of the present cases, left pulmonary artery agenesis was detected but no coexisting cardiac pathologies were found.

Although approximately $30 \%$ of the patients with pulmonary artery agenesis may remain asymptomatic during their lifetime, they can present with serious pulmonary hypertension and congestive heart failure $(7,8)$. Harkel et al. (7) detected symptoms in the $87 \%$ of the cases and found that recurrent lung infections (37\%), decreased exercise tolerance, and dyspnea (40\%) occurred more frequently. Infections are generally moderate, but they can also be 
as destructive as those in necrotizing pneumonia (9). Its etiology is multifactorial. Decreased blood flow in the affected lung prevents the release of proper inflammatory cells at the inflammation zone and causes the loss of ciliary function. Moreover, decreased blood flow leads to alveolar hypocapnia and secondary bronchoconstriction. Chronic infection results in the development of bronchiectasis eventually. Frequently observed infections in some patients are associated with the development of bronchiectasis $(10,11)$. Although we observed shortness of breath and restricted exercise in all of our patients, four patients had bronchiectasis. It was learned that the patients with bronchiectasis had experienced frequent infection seizures since their childhood and one patient had been treated for tuberculosis.

Shakibi et al. (12) reported the prevalence of hemoptysis as $18-20 \%$. In the lung of the affected side, pulmonary arteries end as blind at the hilus and the blood support to the lung comes primarily from main bronchial arteries and then intercostal, internal mammarian, subclavian, and transpleural branches of the innominate arteries. Hemoptysis develops because of the bleeding of the ectatic collateral circulation exposed to hypertrophy into the submucosa of the bronchioles $(3,8)$. Hemoptysis can be massive and fatal, especially in adults $(13,14)$. When it is massive, embolization to systemic collaterals can occur. If there are recurrent hemoptyses in the patient, embolization may be risky and pneumonectomy or lobectomy may be necessary. In the literature, cases that required resectional surgery at a young age, especially because of massive hemoptysis, were reported (15-17). In two of our cases, massive hemoptysis was observed; pneumonectomy was performed for one case and blood transfusion for the other.

Another complication that affects mortality in pulmonary artery agenesis is pulmonary hypertension. In a review, 25 of 57 patients had high pulmonary arterial pressure and in other studies, pulmonary hypertension was found at the rate of $20 \%-25 \%(12,18)$. Harkel et al. (7) reported this rate as $44 \%$ in their study. Some asymptomatic patients who developed pulmonary hypertension become symptomatic in high altitude or during pregnancy. Especially, mortality due to pulmonary hypertension in pregnancy is very high (19). Four of our cases were evaluated for pulmonary hypertension and PAPs was found to be higher in two patients.

The diagnosis of pulmonary artery agenesis is difficult. In radiological screening, the first important findings are observed on chest X-ray. The volume of affected hemithorax is decreased, an increase in ventilation is found, and the hilus is typically either decreased or disappeared. The mediastinal structures, heart, and trachea replace toward the part where agenesia is present, the hemidiaphragm is raised, and the intercostal spaces are narrowed. In the other lung, there is ventilation increase and hilar enlargement (20). When pulmonary arterial agenesis is suspected on the basis of these findings, it is required to validate the diagnosis with ECO and to evaluate other cardiovascular abnormalities and pulmonary hypertension. Another method used in diagnosis is V/Q scintigraphy (2). In these patients, when ventilation is normal, perfusion is not observed. Bouros et al. (29) used chest X-ray, V/Q scintigraphy, digital subtraction angiography, CT, and MR as well as patient history and clinical findings for diagnosis in their pulmonary artery agenesis series that included six cases. They reported that the patients had been misdiagnosed with tuberculosis,
Swyer-James (MacLeod) syndrome, lung tumor, hypoplastic lung, and Fallot tetralogy. In Swyer-James syndrome, there are symptoms and radiologic images seen in pulmonary artery agenesis (21). The final diagnosis is established with ECO and V/Q scintigraphy. Although perfusion is not seen in agenesis cases in the scintigraphic analysis, ventilation is present. A decrease in both of them is present in SwyerJames syndrome (22). Different from agenesis, in hypoplastic lung, the convex abnormal vein, which looks like Turkish sword or machete (scimitar shadow), is present at the lower part of the right lung and abnormality is seen in the drained veins (23). Pulmonary angiography is used for the differential diagnosis of another important pathology, chronic thromboembolism (22).

Pulmonary angiography, which is accepted as golden standard in the diagnosis of pulmonary arterial agenesis is not recommended anymore, except in cases who undergo surgery because of hemoptysis and severe infection, owing to the developments in CT and MR technologies since 1990 (24). These radiological methods that aid the diagnosis of pulmonary artery agenesis also show the collateral veins between systemic-pulmonary arteries causing hemoptysis (1).

There is no consensus in treatment. It is suggested that asymptomatic cases should be followed up with ECO intermittently in terms of the development of pulmonary hypertension (2). If pulmonary hypertension develops, the prognosis of the disease is poor and this causes severe shortness of breath, weight loss, and restricted exercise. If right heart failure develops, insufficiency findings such as peripheral edema, jugular venous distension, and acid stand out. Revascularization with the artery at the hilus of the side with artery agenesis can be a treatment option in chosen cases. This method was used for two cases who were 3 and 21 years old and developed severe pulmonary hypertension and congestive heart failure, and in these patients, pulmonary arterial pressure turned back to normal and heart failure was healed (25).

\section{CONCLUSION}

Diagnosis of pulmonary artery agenesis is very important because it causes severe complications that can result in mortality. In such cases, if typical radiological appearances with necrotizing pneumonia, hemoptysis, pulmonary hypertension, right heart failure, and bronchiectasis are present, primarily pulmonary artery agenesis should be suspected and radiological diagnostic methods should be used for this suspect.

Informed Consent: Due to the retrospective design of the study, informed consent was not taken.

Peer-review: Externally peer-reviewed.

Author contributions: Concept - S.B., M.A.; Design - S.B., T.Y., H.G., M.A.; Supervision - M.A., S.B., H.G., T.Y.; Resource - S.B.; Data Collection and/or Processing - S.B., M.D.; Analysis and/or Interpretation - M.A., S.B.; Literature Search - H.G., T.Y.; Writing - M.A., F.T., M.D.; Critical Reviews - M.A.

Conflict of Interest: No conflict of interest was declared by the authors.

Financial Disclosure: The authors declared that this study has received no financial support.

\section{REFERENCES}

1. Hansell DM, Armstrong P, Lynch DA, McAdams HP, Bankier AA. Congenital anomalies. In: Imaging of diseases of the chest. $4^{\text {th }}$ ed. Philadelphia: Elsevier Mosby; 2005.p.1105. 
2. Reading DW, Oza U. Unilateral absence of a pulmonary artery: a rare disorder with variable presentation. Proc (Bayl Univ Med Cent) 2012; 25: 115-8.

3. Frantzel O. Angeborener Defect der Rechten Lungetarnerie. Virchows Arch Pathol Anat 1868; 43: 420.

4. Zylak CJ, Eyler WR, Spizarny DL, Stone CH. Developmental lung anomalies in the adult: radiologic-pathologic correlation. Radiographics 2002; 22: 25-43. [CrossRef]

5. Heper G, Korkmaz ME. High-pressure pulmonary artery aneurysm and unilateral pulmonary artery agenesis in an adult. Tex Heart Inst J 2007; 34: 425-30.

6. Günen H, Kızkın Ö, Hacıevliyagil SS. Left Pulmonary Artery Hypoplasia with Left Upper Lobe Atelectasis. Turkish Respiratory Journal 2003; 4: 135-7.

7. Ten Harkel AD, Blom NA, Ottenkamp J. Isolated unilateral absence of a pulmonary artery: a case report and review of the literature. Chest 2002; 122: 1471-7. [CrossRef]

8. Toews WH, Pappas G. Surgical management of absent right pulmonary artery with associated pulmonary hypertension. Chest 1983; 84: 497-9. [CrossRef]

9. Canver CC, Pigott JD, Mentzer RM Jr. Neonatal pneumonectomy for isolated unilateral pulmonary artery agenesis. Ann Thorac Surg 1991; 52: 294-5. [CrossRef]

10. Kadir IS, Thekudan J, Dheodar A, Jones MT, Carroll KB. Congenital unilateral pulmonary artery agenesis and aspergilloma. Ann Thorac Surg 2002; 74: 2169-71. [CrossRef]

11. Griffin N, Mansfield L, Redmond KC, Dusmet M, Goldstraw P, Mittal TK, et al. Imaging features of isolated unilateral pulmonary artery agenesis presenting in adulthood: a review of four cases. Clin Radiol 2007; 62: 23844. [CrossRef]

12. Shakibi JG, Rastan H, Nazarian I, Paydar M, Aryanpour I, Siassi B. Isolated unilateral absence of the pulmonary artery. Review of the world literature and guidelines for surgical repair. Jpn Heart J 1978; 19: 439-51. [CrossRef]

13. Thompson JW, Nguyen CD, Lazar RH, Stocks RM, Schoumacher RA, Hamdan $\mathrm{F}$, et al. Evaluation and management of hemoptysis in infants and children: a report of nine cases. Ann Otol Rhinol Laryngol 1996; 105: 51620. [CrossRef]
14. Herraiz Sarachaga I, Perez Gonzalez W, Vergara Rodriguez F, Alonso Lastra MJ, Acerete Guillen F, Bermudez-Canete Fernandez R, et al. Unilateral agenesis of the pulmonary artery. Experience with 4 cases. An Esp Pediatr 1993; 38: 139-44.

15. Taguchi T, Ikeda K, Kume K, Nagasaki A, Goto S, Matsuo S, et al. Isolated unilateral absence of left pulmonary artery with peribronchial arteriovenous malformation showing recurrent hemoptysis. Pediatr Radiol 1987; 17:316-8. [CrossRef]

16. Mehta AC, Livingston DR, Kawalek W, Golish JA, O'donnell JK. Pulmonary artery agenesis presenting as massive hemoptysis- a case report. Angiology 1987; 38: 67-71. [CrossRef]

17. Farghly $E$, Bousamra $M 2$ nd. Hemoptysis resulting from unilateral pulmonary artery agenesis. Ann Thorac Surg 2002; 74: 255-7. [CrossRef]

18. Pool PE, Vogel JH, Blount SG Jr. Congenital unilateral absence of a pulmonary artery. The importance of flow in pulmonary hypertension. Am J Cardiol 1962; 10: 706-32. [CrossRef]

19. Stiller RJ, Soberman S, Turetsky A, Lockwood C, Haddad R. Agenesis of the pulmonary artery: an unusual cause of dyspnea in pregnancy. Am J Obstet Gynecol 1988; 158: 172-3. [CrossRef]

20. Bouros $D$, Paré $P$, Panagou $P$, Tsintiris $K$, Siafakas $N$. The varied manifestation of pulmonary artery agenesis in adulthood. Chest 1995; 108: 670-6. [CrossRef]

21. Marti-Bonmati L, Ruiz Perales F, Catala F, Mata JM, Calonge E. CT findings in Swyer-James syndrome. Radiology 1989; 172: 477-80. [CrossRef]

22. Fraser RS, Müller NL, Colman N, Pare PD. Developmental anomalies affecting the pulmonary vessels. In: Fraser RS, Pare PD, Eds. Fraser and Pare's Diagnosis of Disease of the Chest. Fourth edition. Philadelphia. WB Saunders Company; 1999: 637-675.

23. Currarino G, Williams B. Causes of congenital unilateral pulmonary hypoplasia: a study of 33 cases. Pediatr Radiol 1985; 15: 15-24. [CrossRef]

24. Hacıevliyagil SS, Günen H, Yetkin Ö, Gülbaş G, Mutlu LC, Kılıç T. Asymptomatic Pulmonary Agenesis: Our Experience with Two Cases. Turkish Respiratory Journal 2006; 7: 31-3.

25. Moreno-Cabral RJ, McNamara JJ, Reddy VJ, Caldwell P. Unilateral absent pulmonary artery: surgical repair with a new technique. Thorac Cardiovasc Surg 1991; 102: 463-5. 